\title{
Editorial: Special issue on the International Conference on Advanced Electromaterials 2011
}

\author{
Il-Doo Kim
}

Published online: 30 January 2013

(C) Springer Science+Business Media New York 2013

The International Conference on Advanced Electromaterials, ICAE-2011, was held in Jeju, Republic of Korea from Nov. 7 to Nov. 10, 2011. The bi-annual ICAE is intended for worldrenowned scholars, researchers and young students so that they may come together and share up-to-date knowledge in fields related to advanced electronic materials. The first conference was attended by approximately 900 attendees from 19 countries.

This special issue presents a collection of 22 articles peerreviewed and selected from the presentations given at ICAE-2011. These papers cover a wide range of topics related to electromaterials.

Many individuals contributed to the success of this special issue. We would like to express our gratitude to all of the authors who submitted their work. We are also grateful to all of the reviewers for their invaluable contributions, including the screening of the submitted manuscripts in a very professional way.

Most importantly, as a guest Editor-in-Chief, I deeply appreciate the six guest editors, Prof. Do-Kyun Kwon (Dept. of Materials Engineering, Korea Aerospace University), Prof. Do Kyung Kim (Dept. of Materials Science and Engineering, KAIST), Prof. Yeon Sik Jung (Dept. of Materials Science and Engineering, KAIST), Prof. Dong-Wan Kim (Dept. of Materials Science and Engineering, Ajou University),
Prof. Kyoung-Jin Choi (School of Mechanical and Advanced Materials Engineering, Ulsan National Institute of Science and Technology), and Prof. Sang-Woo Kim (School of Advanced Materials Science \& Engineering, Sungkyunkwan University) for their assistance with the creation of this special issue and for their help in managing the manuscript review process. Without their dedication, this special issue could not have succeeded nearly as well.

We are especially grateful to the Journal of Electroceramics for the opportunity to put together this special issue as a first volume of 2013.

Finally, I would like to thank Michael Luby, Publishing Editor/Publishing Contact at Springer, and Prof. Harry L. Tuller at Massachusetts Institute of Technology, Editor-inChief of Journal of Electroceramics, for offering us this opportunity and for patiently waiting for the completion of the special issue, and Editorial Assistant, Anne Medina and Production Editor, Jona Rose Y. de los Nieves, for their constant assistance in editorial matters.

We hope that you find the ICAE special issue very helpful to your ongoing research activities.

Il-Doo Kim

Guest Editor-in-Chief

Journal of Electroceramics

I.-D. $\operatorname{Kim}(\triangle)$

Department of Material Science and Engineering,

Korea Advanced Institute of Science and Technology (KAIST),

291 Daehak-roYuseong-gu Daejeon 305-701, Republic of Korea

e-mail: idkim@kaist.ac.kr 